\title{
BIPOLAR PLASMA VAPORIZATION VERSUS QUARTZ HEAD LASER ABLATION OF THE PROSTATE FOR THE TREATMENT OF BENIGN PROSTATEHYPERPLASIA: A COMPARATIVE STUDY OF OUTCOME AND COMPLICATIONS
}

\author{
Hassan S. Shaker*, Hisham M.El Shawaf*, Mohamed Abu El Naga*, \\ Mohamed A. Abd El Hamid**
}

\author{
*Department of Urology, Faculty of \\ Medicine, Ain shams University \\ ** Urologist at Shoubra General \\ Hospital \\ Corresponding: \\ Mohamed Abd El Hamid \\ Mobile 01060002645 \\ Email: \\ D_Mohamedeid@yahoo.com \\ Received: $18 / 2 / 2020$ \\ Accepted: 10/3/2020
}

Online ISSN: 2735-3540

\section{ABSTRACT:}

Background: Benign prostatic hyperplasia (BPH) is considered one of the most common causes of lower urinary tract symptoms (LUTS), urinary obstruction and urinary retention which usually occurs above age of 40 years.

Aim of the Work: to compare the short term effectiveness and complications of bipolar plasma versus laser vaporization of prostate over 6 months duration of follow up post-operative.

Patients and Methods: This prospective comparative clinical study (double armed) included 128 patients with prostates less than 80 gm operated upon and followed up in the Urology Department of Ain shams University hospitals in the period from September 2015 to January 2018. The patients were divided into 2 groups: Group A 64 patients who underwent Plasma vaporization. Group B 64 Patients who underwent Quartz Laser Ablation of prostate (QLAP).

Results: There were statistically significant differences between both groups as regards prostate volume reduction, PSA reduction and decrease in postvoiding residual urine more in the laser group. While IPSS and QOL reduction and uroflowmetry improvement showed higher improvement in the plasma group.

Conclusion: both techniques whether laser vaporization or plasma vaporization are considered safe, effective minimally invasive procedure in managing prostatic enlargement indicated for surgery. Both techniques are similar in the outcome and both lead to improvement of all parameters of prostatic symptoms. Laser vaporization looks to be faster, has stronger power to vaporize more tissues than plasma. No serious complications occurred in both groups. Nevertheless complications are more frequent in the plasma group.

Key words: bipolar plasma vaporization, laser vaporization, prostate, benign prostate hyperplasia

\section{INTRODUCTION:}

Transurethral resection of the prostate (TURP) was considered the gold standard therapeutic approach in cases of average size prostate (30-80 grams) ${ }^{1}$
However, one of the most important problems associated with TURP is the intraoperative bleeding and the possibility of blood transfusion, particularly in patients on anticoagulants treatment. Furthermore TURP is a difficult procedure to perform 
safely and has a steep learning curve. Moreover intravasation of hypotonic fluid and risk of TUR syndrome is high in large prostates ${ }^{2}$.

New techniques have been emerged to overcome the drawbacks of TURP, one of them is bipolar plasma vaporization, which is a newly introduced technique in the field of transurethral surgery of prostate that uses bipolar energy in resection and/or vaporization of enlarged prostate gland ${ }^{\mathbf{3}}$.

Plasma vaporization enablesus to vaporize the prostate gland tissue by creation of an ionized plasma corona, using an axipolar electrode and electro-conductive solutions (normal saline). The active and return electrodes of the loop bend in the same axis. The use of normal saline irrigation $(\mathrm{NaCl} 0.9 \%)$ instead of hypotonic solution to decrease the overall morbidity associated with TURP , and eliminate risk of TUR syndrome associated with prolonged resection time is the main supposed advantage. Also coagulation of blood vessels gives better hemostatic results ${ }^{4}$.

Also many laser devices were introduced in clinical practice during the past years that were employed in vaporization of prostate, and main groups of laser device system scurrently used include KTP (potassium titanyl phosphate, KTP: Nd: YAG) , LBO (lithium borat, LBO: Nd: YAG ), Diode lasers, Holmium yttrium-aluminumgarnet laser (Ho: YAG) and Thulium YAG $(\mathrm{Tm}-\mathrm{YAG})^{5}$.

All of these transurethral laser operations work in a physiologic sodium solution $0.9 \%$ for irrigation, this eliminates the risk of dilutional hyponatremia TUR syndrome that has been reported in TURP series. Furthermore, they offer the advantage of decreased intraoperative bleeding and thus to treat patients with bleeding disorders or on anti-coagulant treatment ${ }^{6}$.

Despite showing excellent results in the literature, some obstacles limit the wide use of laser. For example, cost concerns in most countries and health care systems, steep learning curve, also the complexity of the procedure especially in Holep (holmium enucleation of prostate) $)^{7}$.

A newly introduced technology in the field of diode laser is the twister fiber (quartz head contact fiber QH). Which differs from the standard side firing original fiber that it is end firing fiber with $30^{\circ}$ degrees angulation at the distal end, which is covered with Quartz. laser waves are not emitted from the fiber but gathered in the quartz end producing heat energy. ${ }^{8}$

QLAP (Quartz Laser ablation of prostate) is considered one of the most efficient, fast and safe procedures with less incidence of complications associated with the standard side firing fiber. Also twister fiber gives the surgeon the same tactile sensation of ordinary resectoscopes ${ }^{\mathbf{8}}$.

\section{AIM OF THE WORK}

To compare the short term effectiveness, safety and complications of bipolarplasma-versus laser vaporization of prostate over 6 months duration of follow up post-operative.

\section{PATIENTS AND METHODS}

This prospective comparative clinical study (double armed) was carried out on 128 patients with prostates less than 80 gm who were operated upon and followed up in the Urology Department of Ain shams University hospitals in the period from September 2015 to January 2018.Our patients were divided into 2 groups: Group A 64 Patients who underwent Plasma vaporization. Group B 64 Patients who underwent QLAP vaporization.

The study included all BPH patients with prostate size less than 80 gm measured by transrectal or pelvic ultrasound and were 
indicated for surgical intervention due to any of the following: patients with LUTS (voiding \pm storage) refractory to medical TTT with IPSS $>20$ (International prostate scoring system) and Q $\max <15 \mathrm{ml}$, refractory acute urinary retention, hematuria or recurrent urinary tract infections 2ry to $\mathrm{BPH}$ and renal impairment 2ry to prostatic obstruction. While patients with prostate size above 80 grams, proved malignancy by biopsy, urethral strictures, urinary bladder stones, previous prostate surgery, urodynamically proved neurogenic bladder, bladder cancer or unfit for anesthesia were excluded from the study.

The patients were informed about the nature of the procedure as a rising technique for management of prostate enlargement and

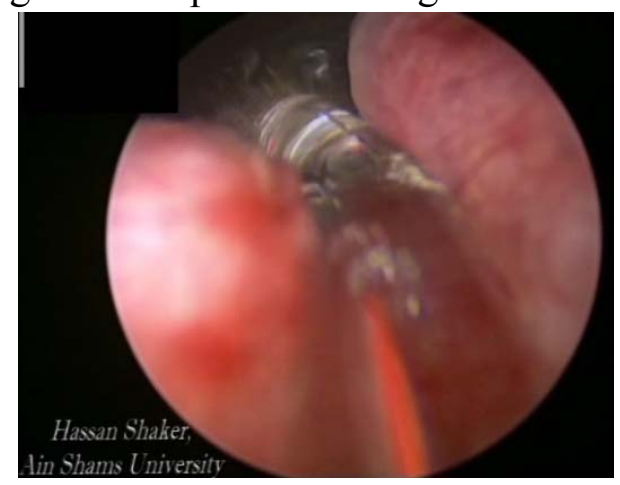

about the different surgical options available. The investigational nature of the study was explained to the patients and all signed an informed consent form. The study protocol was approved by the local ethics committee of the hospital.

\section{Methods of the study:}

Preoperative: detailed history taking including international prostate scoring system (IPSS), sexual and ejaculatory history, careful clinical examination including digital rectal examination (DRE). Trans rectal U/S was performed to confirm clinical examination and estimating post voiding residual urine (PVRU) and uroflometry. Laboratory investigations included (hemoglobin - PSA - creatinine - Na-K).

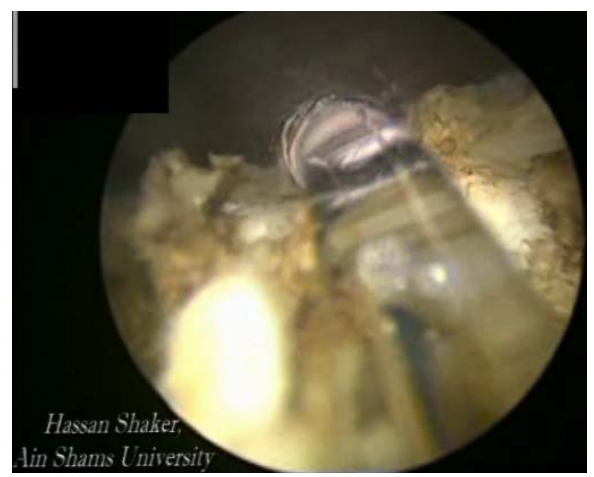

Figure (1): Laser vaporization of prostate
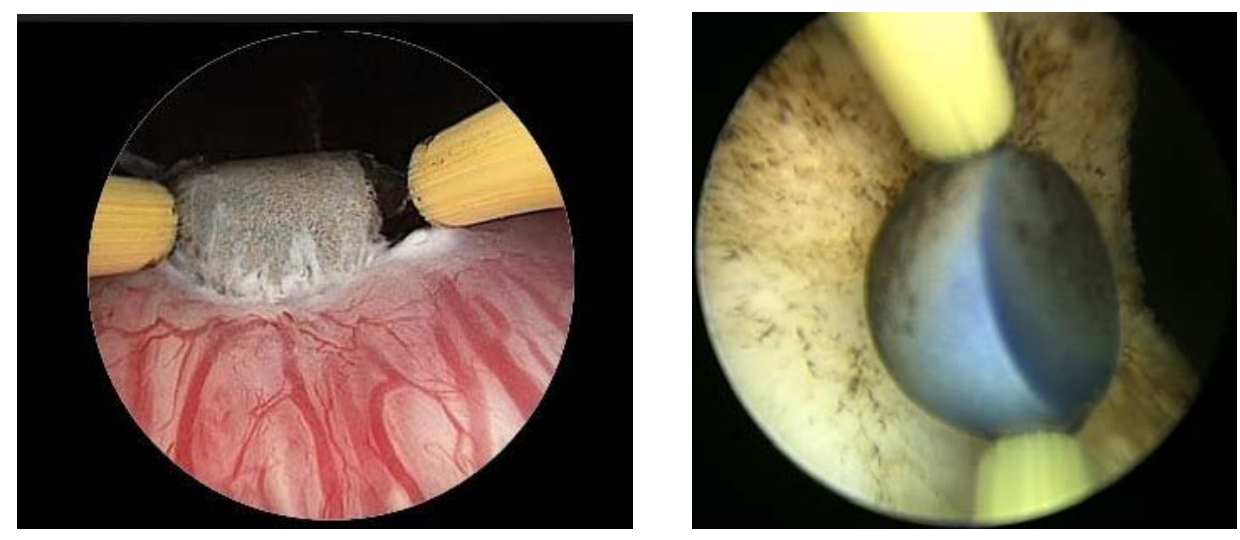

Figure (2): Plasma vaporization of prostate

Intraoperative: Time of operation and recording of any complications. Plasma kinetic vaporization was done using a Storz $26 \mathrm{Fr}$ continuous irrigation resectoscope with plasma kinetic wedge -like electrode using the bipolar current and normal saline irrigation.3 - Laser prostatectomy using Diode Laser system (Ceralas HPD 400 from Biolitec-AG) emitting $980 \mathrm{~nm}$ wavelength laser was used as a source of the Laser. The 
fiber used is the newly introduced twister fiber the extra-large one LTW, also normal saline is used for irrigation.

Postoperative: catheter time and hospital stay, changes in electrolytes, hemoglobin level and the need for blood transfusion, early post-operative follow up (after one month) for detection of early complications (dysuria - overactive bladder symptoms - hematuria).

Follow up was doneat 6 months with repeating IPSS, PSA level, uroflometry and $\mathrm{U} / \mathrm{S}$ (for post voiding residual)

\section{Statistical methods}

Data management and statistical analysis were done using SPSS vs.25. (IBM, Armonk, New York, United states). Numerical data was summarized as means and standard deviations or medians and ranges. Categorical data was summarized as numbers and percentages. General characteristics were compared between both groups using independent $t$ test for numerical data. Chi-square test was used for categorical data. Clinical and laboratory findings were compared preoperatively and at 6 months using paired t test or Wilcoxon signed ranks test for normally and non-normally distributed numerical data respectively. McNemar test was used for comparing categorical data pre-operatively and at 6 months. Percent Change in clinical and laboratory findings at 6 months were compared between both groups using Mann Whitney $U$ test. Complications were compared using Chi-square test or Fisher's exact test. All $\mathrm{P}$ values were two sided. $\mathrm{P}$ values less than 0.05 were considered significant.

\section{RESULTS:}

Table (1): Pre operative comparison in both groups

\begin{tabular}{|l|c|c|c|}
\hline Parameters & Group I & Group II & p-value \\
\hline Pre IPSS total & $30(21-34)$ & $18(9-32)$ & $<0.001$ \\
\hline Median (Range) & & & \\
\hline Pre IPSS QOL & $5(3-6)$ & $4(2-5)$ & $<0.001$ \\
\hline Median (Range) & $63.2 \pm 12.4$ & $63.6 \pm 16.1$ & 0.870 \\
\hline Pre size & \multicolumn{3}{|l|}{} \\
\hline Mean \pm SD & $90(15-720)$ & 0.034 \\
\hline Pre PVR & $9.6 \pm 3.1$ & $<0.001$ \\
\hline Median (Range) & $173(20-500)$ & $2(0.6-12.5)$ & 0.301 \\
\hline Pre Qmax & $6.3 \pm 2$ & 0.200 \\
\hline Mean \pm SD & $3.6(0.8-30)$ & $12.7 \pm 1.7$ & 0.057 \\
\hline Pre PSA & $13.1 \pm 1.6$ & $139 \pm 2$ & \\
\hline Median (Range) & $137 \pm 4$ & & \\
\hline Pre Hb &
\end{tabular}

This table demonstrates pre operative comparison between both groups and shows that there is no significant difference between both groups regarding: preoperative But there is significant difference between both groups regarding IPSS total, IPSS QOL ,residual urine volume, and Q$\max$. prostate size, PSA, hemoglobin and sodium level. 
Clinical and laboratory findings in group A

There was significant improvement to all the patient subjected to plasma vaporization of prostate as regard IPSS that drops dramatically from 30 (median) to 10 after 6 months, also there was improvement in quality of life index. Ultrasound confirmed this improvement by decrease in prostate size by about $34.1 \%$ and reduction in post voiding residual urine amount 58.5\%. Also Qmax increased from 6.3 $\mathrm{ml} / \mathrm{sec}$ (median) to $13.3 \mathrm{ml} / \mathrm{sec}$ percentage of change $(120 \%)$. There was statistically significant change in hemoglobin, sodium and potassium levels early post-operative but it was of no clinical value. PSA level decreased by $35.7 \%$ six months postoperative

Table (2): Clinical and laboratory findings pre-operative and at 6 months in group A

\begin{tabular}{|c|c|c|c|c|}
\hline & & & & $\mathrm{P}$ value \\
\hline \multirow[t]{2}{*}{ IPSS total } & Pre & Median (range) & $30(21-34)$ & $<0.001$ \\
\hline & At 6 months & Median (range) & $10(7-18)$ & \\
\hline \multirow[t]{2}{*}{ IPSS QOL } & Pre & Median (range) & $5(3-6)$ & $<0.001$ \\
\hline & At 6 months & Median (range) & $2(1-4)$ & \\
\hline \multirow[t]{2}{*}{ Size } & Pre & Mean \pm SD & $63.2 \pm 12.4$ & $<0.001$ \\
\hline & At 6 months & Mean \pm SD & $41.7 \pm 8.5$ & \\
\hline \multirow[t]{2}{*}{ PVR } & Pre & Median (range) & $173(20-500)$ & $<0.001$ \\
\hline & At 6 months & Median (range) & $80(10-240)$ & \\
\hline \multirow[t]{2}{*}{ Qmax } & Pre & Mean \pm SD & $6.3 \pm 2$ & $<0.001$ \\
\hline & At 6 months & Mean \pm SD & $13.3 \pm 2.1$ & \\
\hline \multirow[t]{2}{*}{ Qavg } & Pre & Mean \pm SD & $3.3 \pm 1.4$ & $<0.001$ \\
\hline & At 6 months & Mean \pm SD & $9 \pm 1.2$ & \\
\hline \multirow[t]{2}{*}{ PSA } & Pre & Median (range) & $3.6(0.8-30)$ & $<0.001$ \\
\hline & At 6 months & Median (range) & $2.1(0.5-7)$ & \\
\hline \multirow[t]{2}{*}{ Hemoglobin } & Pre & Mean \pm SD & $13.1 \pm 1.6$ & $<0.001$ \\
\hline & post & Mean \pm SD & $12.7 \pm 1.6$ & \\
\hline \multirow[t]{2}{*}{$\mathrm{Na}^{++}$} & Pre & Mean \pm SD & $137 \pm 4$ & $<0.001$ \\
\hline & post & Mean \pm SD & $138 \pm 4$ & \\
\hline \multirow[t]{2}{*}{$\mathrm{K}^{+}$} & Pre & Mean \pm SD & $4.12 \pm 0.7$ & $<0.001$ \\
\hline & post & Mean \pm SD & $4.06 \pm 0.6$ & \\
\hline
\end{tabular}

Clinical and laboratory findings in group B

Patients in this group showed significant improvement in their symptoms score and QOL (Median IPSS total decreased from 18 preoperative to 8) at 6 months. Uroflowmetry parameters improved Qmax increased from $9.6 \mathrm{ml} / \mathrm{sec}$ to $18 \mathrm{ml} / \mathrm{sec}$. This was statistically significant. Also ultrasound scanning showed reduction in prostate size by $72 \% 6$ months later, and decrease of PVR from $80 \mathrm{ml}$ to $13 \mathrm{ml}$, this was statistically significant. Also there was reduction in PSA level by $84.5 \%$.

There was a statistically significant change in levels of hemoglobin, sodium and potassium post-operative but this was of no clinical value. 
Hassan S. Shaker, et al.,

Table (3):Clinical and laboratory findings pre-operative and at 6 months in group B

\begin{tabular}{|c|c|c|c|c|}
\hline & & & & $\mathrm{P}$ value \\
\hline \multirow[t]{2}{*}{ IPSS total } & Pre & Median (range) & $18(9-32)$ & $<0.001$ \\
\hline & At 6 months & Median (range) & $8(5-24)$ & \\
\hline \multirow[t]{2}{*}{ IPSS QOL } & Pre & Median (range) & $4(2-5)$ & $<0.001$ \\
\hline & At 6 months & Median (range) & $2(1-6)$ & \\
\hline \multirow[t]{2}{*}{ Size } & Pre & Mean \pm SD & $63.6 \pm 16.1$ & $<0.001$ \\
\hline & At 6 months & Mean \pm SD & $20.7 \pm 9.9$ & \\
\hline \multirow[t]{2}{*}{ PVR } & Pre & Median (range) & $80(15-720)$ & $<0.001$ \\
\hline & At 6 months & Median (range) & $13(0-177)$ & \\
\hline \multirow[t]{2}{*}{ Qmax } & Pre & Mean \pm SD & $9.6 \pm 3.1$ & $<0.001$ \\
\hline & At 6 months & Mean \pm SD & $18 \pm 9.4$ & \\
\hline \multirow[t]{2}{*}{ Qavg } & Pre & Mean \pm SD & $5.7 \pm 1.7$ & $<0.001$ \\
\hline & At 6 months & Mean \pm SD & $10 \pm 4.6$ & \\
\hline \multirow[t]{2}{*}{ PSA } & Pre & Median (range) & $2(0.6-12.5)$ & $<0.001$ \\
\hline & At 6 months & Median (range) & $0.21(0.15-2.1)$ & \\
\hline \multirow[t]{2}{*}{ Hemoglobin } & Pre & Mean \pm SD & $12.7 \pm 1.7$ & 0.002 \\
\hline & post & Mean \pm SD & $11.5 \pm 1.2$ & \\
\hline \multirow[t]{2}{*}{$\mathrm{Na}^{++}$} & Pre & Mean \pm SD & $139 \pm 2$ & $<0.001$ \\
\hline & post & Mean \pm SD & $136 \pm 4$ & \\
\hline \multirow[t]{2}{*}{$\mathrm{K}^{+}$} & Pre & Mean \pm SD & $4.06 \pm 0.6$ & 0.77 \\
\hline & post & Mean \pm SD & $4.09 \pm 0.4$ & \\
\hline
\end{tabular}

Percent change in clinical and laboratory findings at 6 months in both groups:

When we compared the results between both groups there was no clinical or statistical difference between the two groups. There was no significant difference in percent of decrease in IPSS total at 6 month between both group $(\mathrm{P}$ value $=$ 0.536). Median percent decrease in IPSS QOL was significantly higher in group A $(66.7 \%)$ compared to group B $(50.0 \%)$ (P value was $<0.001)$. Median percent decrease in size was significantly higher in group B (72.0\%) compared to group A (34.1\%) (P value was. $<0.001)$.

Median percent decrease in PVR was significantly higher in group B $(80.0 \%)$ compared to group A $(58.5 \%)$. P value was $<0.001$
Median percent change in Qmax was significantly higher in group A $(120 \%)$ compared to group B $(106 \%)$. (P value was $<0.001)$. Median percent change in Qavg was significantly higher in group A (196.0\%) compared to group B (103\%). (P value was $<0.001)$.Median percent decrease in PSA was significantly higher in group B $(84.5 \%)$ compared to group A $(35.7 \%)$. (P value was $<0.001$ ).

There was no significant difference in percent change in hemoglobin between both group $(\mathrm{P}$ value $=0.077)$. Median percent change in sodium was $0.7 \%$ in group $\mathrm{A}$ compared to $-1.4 \%$ in group $\mathrm{B}$. $\mathrm{P}$ value was $<0.001$. There was no significant difference in percent change in potassium between both group $(\mathrm{P}$ value $=0.079)$. 
Bipolar plasma vaporization versus quartz head laser ablation of the prostate for the treatment of..

Table (4): Comparison of change in clinical and laboratory findings at 6 months in both groups

\begin{tabular}{|l|c|c|c|}
\hline & Group A (n=64) & Group B (n=64) & P value \\
\hline & Median (range) & Median (range) & 0.536 \\
\hline$\%$ decrease in IPSS total & $66.7(37.9-79.4)$ & $67.7(42.1-84.4)$ & $<0.001$ \\
\hline$\%$ decrease in IPSS QOL & $66.7(20-83.3)$ & $50(25-66.7)$ & $<0.001$ \\
\hline$\%$ decrease in Size & $34.1(27.5-44)$ & $72(20.2-87.5)$ & $<0.001$ \\
\hline$\%$ decrease in PVR & $58.5(20-92.8)$ & $80(22.9-100)$ & $<0.001$ \\
\hline$\%$ change in Qmax & $120(-2.3-294.1)$ & $106(-24-850)$ & $<0.001$ \\
\hline$\%$ change in Qavg & $196(6.7-790.9)$ & $103(-16.7-151.5)$ & $<0.001$ \\
\hline$\%$ change in Hemoglobin & $35.7(0-81.3)$ & $84.5(40-98)$ & 0.077 \\
\hline$\%$ change in Na & $-2.8(-11.1-0.7)$ & $-5.9(-14.3-15.9)$ & $<0.001$ \\
\hline$\%$ change in $\mathrm{K}^{+}$ & $0.7(-1.4-2.2)$ & $-1.4(-5.6-2.1)$ & 0.079 \\
\hline
\end{tabular}

Table (5): Operation time in both groups

\begin{tabular}{|l|l|c|c|c|}
\hline & & $\begin{array}{c}\text { Group A } \\
(\mathrm{n}=64)\end{array}$ & $\begin{array}{c}\text { Group B } \\
(\mathrm{n}=64)\end{array}$ & P value \\
\hline Operation time (min) & Mean \pm SD & $50 \pm 12$ & $29 \pm 11$ & $<0.001$ \\
\hline
\end{tabular}

Independent $t$ test was used

\section{$>$ Operation time in both groups:}

Mean operation time was significantly higher in group A (50 minutes) compared to group $\mathrm{B}$ (29 minutes). $\mathrm{P}$ value was $<0.001$

\section{Complications in both groups}

There was no significant fluid absorption during the procedure thus, none of our patients developed TUR syndrome or had any intraoperative event denoting circulatory overload.

No significant bleeding occurred in any patient, confirmed by post-operative hemoglobin monitoring, and subsequently no need for blood transfusion.

Post-operative retention after catheter removal occurred in 14 patient in plasma Table (6): Classification of complications according to number \& percentage and Claviandindo classification

\begin{tabular}{|l|c|c|c|c|c|c|}
\hline & \multicolumn{3}{|c|}{ Group I } & \multicolumn{3}{c|}{ Group II } \\
\hline & $\mathrm{N}$ & $\%$ & $\mathrm{CD}$ & $\mathrm{N}$ & $\%$ & CD \\
\hline one month dysuria & 40 & 62.5 & CD I & 33 & 51.6 & CD I \\
\hline one month OAB & 18 & 28.1 & CD I & 14 & 21.9 & CD I \\
\hline one month hematuria & 5 & 7.8 & CD I & 3 & 4.7 & CD I \\
\hline Persistent dysuria & 8 & 12.5 & CD II & 3 & 4.7 & CD II \\
\hline persistent OAB & 16 & 25.0 & CD II & 12 & 18.8 & CD II \\
\hline urethral stricture & 4 & 6.3 & CD III & 6 & 9.4 & CD III \\
\hline Meatal stenosis & 1 & 1.6 & CD III & 0 & 0.0 & 0 \\
\hline BNC & 5 & 7.8 & CD III & 4 & 6.3 & CD III \\
\hline Redo & 2 & 3.12 & CD III & 0 & 0 & 0 \\
\hline Retention & 14 & 21.8 & CD II & 8 & 12.5 & CD II \\
\hline
\end{tabular}

group representing $21.8 \%$ of total group, and occurred in 8 patients in laser group representing $12.5 \%$ of this group. Another trial of catheter removal and trial of voiding after one week which was successful and the patients were able to void normally. This was not statistically significant.

Only 2 patients in plasma group (3.12 $\%$ ) required reoperation another time. Also this was of no statistical significant.

There were no statistically significant differences between both groups as regard all complications, neither the early one month complication nor the late (6 months) complications. 
Hassan S. Shaker, et al.,

Table (7): Number of complications in each group according to Claviandindo classification

\begin{tabular}{|c|c|c|c|c|}
\hline & No complications & CD I & CD II & CD III \\
\hline Plasma & 5 & 23 & 24 & 12 \\
\hline Laser & 22 & 17 & 15 & 10 \\
\hline
\end{tabular}

There was statistically significant difference in the total number of complications between the two groups ( $p$ value 0.003 ). The number was higher in plasma group.

\section{DISCUSSION:}

$\mathrm{BPH}$ can lead to enlargement of the size of prostate BPE (benign prostatic enlargement). This enlargement can lead to obstruction at the level of bladder neck. BOO (bladder outlet obstruction) may be caused by other conditions. Parallel to this anatomical and functional processes, LUTS (lower urinary tract symptoms) occurs. LUTS increase in frequency and severity with age. LUTS can be caused by a variety of conditions. LUTS rather than BPH is the target of intervention?.

For those with small and medium sized prostates $(30-80 \mathrm{~mL})$ monopolar transurethral resection of the prostate (M-TURP) is still the gold standard operation for managing moderate-to-severe lower urinary tract symptoms (LUTS) secondary of benign prostatic obstruction (BPO), despite the introduction of newer safer alternative procedures. Although excellent results have been reported for M-TURP, some patients with high risk of bleeding, comorbidities, or big prostates are not considered candidates ${ }^{\mathbf{1 0}}$.

The Gyrus Plasma Kinetic (PK) system, the first bipolar device, has become widely used in urology, this device uses an axipolar electrode and electro conductive solutions to create an ionized plasma corona and uses saline rather than glycine or sorbitol as an irrigate, greatly reducing the risk of blood loss and transurethral resection syndrome ${ }^{11}$.

The diode laser, which was approved by FDA in the USA in 2007, has been widely used due to its high vaporization capacities and excellent coagulation properties. The wavelength of this laser is $980 \mathrm{~nm}$, simultaneously absorbed by both water and hemoglobin, and the laser provides high tissue ablation capacity with good hemostasis. Therefore, the diode laser can significantly improve both the International Prostate Symptom Score (IPSS) and Qmax without the major side effects of M-TURP as we use normal saline as irrigation fluid ${ }^{\mathbf{1 1}}$.

Most of studies and literature compared the two arms of our study (plasma or laser) versus the ordinary monopolar TURP. And show more safety and efficacy and less side effects on patients. No previous studies compared the $980 \mathrm{~nm}$ diode laser vaporization and plasma vaporization of prostate.

In this study we tried to evaluate the safety and efficacy of bipolar plasma vaporization in the treatment of patients with prostates less than $80 \mathrm{gm}$, in comparison to laser vaporization using diode laser $980 \mathrm{~nm}$ with quartz headed fiber (QLAP). Our patients were divided into two groups: group I operated by plasma and group II operated by laser, we tried to compare the intraoperative, early postoperative and 6 months follow up results of both groups.

Our study included 130 patients with a mean age of $67.65( \pm 7.05)$ years. We did not put any restrictions concerning the age of the patients in our study which ranged from 48 to 85 years. We observed that the safety or efficacy of the procedure was not affected by this variation in the patient age. In general there was no significant difference in the demographic preoperative data in both groups (age, associated co morbidities, preoperative data like prostate size, hemoglobin, electrolytes, PSA). 
In a study was performed by El-Tabey et al., 2015 over 60 patients with lower urinary tract symptoms (LUTS) due to benign prostatic hyperplasia $(\mathrm{BPH})$ underwent transurethral vaporization of prostate using bipolar plasma vaporization energy concluded that, during the period of follow up in three months, function outcomes such as IPSS, Quality of life, Qmax and PVRU were excellently improved as compared to the baseline of these parameters ${ }^{12}$.

Regarding the early post-operative complications, our results revealed that urinary retention requiring catheterization occurred in 14 patients after PKVP, only two of them failed to void in the second trial of voiding required redo operation and vaporization of residual anterior tissues. The large number of retention post PVP can be explained by the irritation of nerve ending by the plasma which is more than cases of monopolar TURP. None of el Tabey et al required reoperation ${ }^{\mathbf{1 2}}$.

In other study of Chen et al 2014 postoperative hematuria occurred in 3 patients only and it resolved by medical treatment. In our study 5 patients developed post-operative hematuria in the first month of follow up none of them required transfusion this can be explained by anticoagulant taken by those patients ${ }^{\mathbf{1 3}}$.

Chen et al study recorded that urethral stricture encountered in two patients that required urethral dilation in an outpatient basis without VIU. In our study 4 patients developed urethral stricture that required VIU this may be caused by lengthy resection time or prolonged catheterization time. Bladder neck contracture occurred in one case and required bladder neck incision. In our study bladder neck contracture occurred in about 4 patients that required later on BNI. This occurred mainly in patients with small sized fibrous prostates with excessive vaporization at bladder neck ${ }^{13}$.
With regard to the occurrence of TUR syndrome, none of our patients experienced TUR syndrome. Using saline as an irrigation solution eliminated this risk. This finding is consistent with several previous studies concerning Plasmakinetic vaporization of prostate and this is considered one of the major advantage of this technique ${ }^{\mathbf{1 3}}$.

As regard laser group a similar study was done by Mithani et al 2018, studying the outcome of $980 \mathrm{~nm}$ diode laser vaporization using Quartz head laser on 110 patients and followed up for 6 months, concluded that there was significant improvement in IPSS that decreased from $25.96 \pm 3.58$ to $7.04 \pm$ 1.69, also Q max increased from $6.13 \pm 1.44$ $\mathrm{ml} / \mathrm{min}$ preoperative to $19.22 \pm 4.75 \mathrm{ml} / \mathrm{min}$ 6 months later. Also post voiding residual urine drops from $131.69 \pm 42.35 \mathrm{ml}$ to 18.89 $\pm 5.39 \mathrm{ml}$. This is similar to our results where IPSS drop from 18 to 8 six months post-operatively, Q max increased from 9.6 $\mathrm{ml} / \mathrm{min}$ to $18 \mathrm{ml} / \mathrm{min}$, and post voiding residual decreased from $80 \mathrm{ml}$ to $13 \mathrm{ml}$ within six months ${ }^{14}$.

Also Mithani et al stated that there was no significant changes were observed in postoperative hemoglobin, sodium and $\mathrm{K}$. The most frequent problems were burning micturition $(35 \%)$ and terminal dysuria $(29 \%)$. The $10 \%$ patients had minor hematuria (not requiring transfusion) and $4 \%$ patients had stress incontinence for few days after successful trial of catheter which were managed conservatively. Similarly, in our study, there was no significant changes in hemoglobin or electrolytes. Dysuria encountered in about $50 \%$ of patients early after one month then decreased gradually to persist only in $4.6 \%$ of the patients 6 months post-operative. Terminal hematuria occurred in 3 patients only $4.7 \%{ }^{14}$.

When we compared both groups of patients there was no great difference between the two group, and both techniques proved great efficiency and safety on patients especially in high risk group of 


\section{Hassan S. Shaker, et al.,}

patients, and both of them resulted in improvement in all parameters of LUTS secondary to BPH (decrease of IPSS, increase of Q max, decrease of residual urine and PSA). As regard the safety of operation, there was no risk or major complication encountered in the study e.g. no significant bleeding or blood transfusion as proved by hemoglobin change in both groups. And no risk of TUR syndrome as we use saline instead of hypotonic solutions, and this was proved by change of sodium pre and postoperative.

However there is some points was observed during the study, where operation time was shorter in laser group 29(mean) min compared to $50 \mathrm{~min}$ in plasma group. Also the need for redo operation occurred in 2 patients of plasma group. Also catheter time was shorter in laser prostatectomy 24 hours versus 48 hours in PVP, this is done in trial to avoid or lessen the irritative effect of plasma on the nerve ending, and avoid the expected dysuria which was more frequent in patients of the PVP group and persist up to 6 months in about 8 patients versus 3 patients only in laser group.

The vaporizing power and the ability to vaporize larger volume of prostatic adenoma seems to be more in laser group as we noticed that the reduction of prostate volume was higher in laser group, also the reduction of PSA was higher in laser group. Beside that the need of reoperation occurred in 2 patients in the plasma group as compared to none in the laser group.

When we assessed the complications of the two groups using claviandindo classification we noticed that the number of patients in each category of this classification was higher in plasma group compared to laser group. This was statistically significant.

Several drawbacks were observed in our study namely, small number of patients, short period of follow up of 6 months, and different surgeons were involved as operators. Patients were not randomized, the IPSS was not self-administered in plasma group but was helped by the researcher to fulfill it. Which makes IPSS \& QOL data unreliable. Also we did not assess the sexual function of patients either pre or postoperative to assess the possible retrograde ejaculation

Therefore, we recommend the future researchers to continue our work and perform the following studies over a larger scale of patients for a longer follow up periods. Furthermore, if possible, to decrease the number of surgeons to avoid the difference of utilized techniques and the difference of skill and experience between the surgeons. Proper randomization of patients will make such study more valuable. IPSS has to be strictly self-administered to all patients involved in the study. Sexual function need to be to probably assessed especially retrograde ejaculation.

\section{Conclusion:}

In this study we concluded that both techniques whether laser vaporization or plasma vaporization are considered safe, effective minimally invasive procedure in managing prostatic enlargement indicated for surgery. Both techniques are similar in the outcome and both lead to improvement of all parameters of prostatic symptoms. Laser vaporization looks to be faster, has stronger power to vaporize more tissues than plasma. No serious complications occurred in both groups. Nevertheless complications are more frequent in the plasma group.

\section{REFERENCES:}

1. Min HL, Hee JY, Doo SK, Chang HL, and Youn SJ. Holmium Laser Enucleation of the Prostate is Effective in the Treatment of Symptomatic Benign Prostatic Hyperplasia of Any Size Including a Small Prostate. Korean J Urol. 2014 Nov; 55 (11): 737-741. 
2. Pankaj NM, Nitin J, and Reeta PM Best laser for prostatectomy in the year 2013.Indian J Urol. 2013 Jul-Sep; 29(3): 236-243.

3. Zhu G, Xie C, Wang X, and Tang X. Bipolar plasmakinetic transurethral resection of prostate in 132 consecutive patients with large gland: three-year follow-up results. Urology. 2012; 79:397-402.

4. Kai W, Yao L, Jing FT, Hai YZ, Dan $\mathrm{FX}$, and Yi F: Transurethral plasmakinetic resection of the prostate is a reliable minimal invasive technique for benign prostate hyperplasia: a metaanalysis of randomized controlled trials. Asian J Androl. 2015 Jan-Feb; 17(1): 135-142.

5. Muschter R. Laser therapy for benign prostate hyperplasia. Aktuelle Urol. 2008; 39(5):339-68.

6. Thomas RW, Bach T. et al. Thulium laser enucleation of the prostate (ThuLEP): transurethral anatomical prostatectomy with laser support. Introduction of a novel technique for the treatment of benign prostatic obstruction. World J Urol. 2010; 28:4551.

7. Gilling $\mathrm{PJ}$, Aho $\mathrm{TF}$, Frampton $\mathrm{CM}$, King CJ, Fraundorfer Mr.: Holmium laser enucleation of the prostate: results at 6 years. Eur Urol, 2008; 53:744-9.

8. 8-Shaker H, Saafan A, Yassin M, Fawzy $M$ and Shoeb M. Safety and Efficacy of Quartz Head Contact Laser Ablation for Large Prostates Using 980- nm Laser: A Comparative Prospective Study Against That for Small- and Medium sized Prostates .J Urol.2014 April.

9. Foster H, Barry M, Dahm P, Gandhi M, Kaplan S, Kohler T, Lerner L, Lightner D, Parsons J, Roehrborn C, Welliver C, Wilt $T$ and McVary K. Surgical Management of Lower Urinary Tract Symptoms Attributed to Benign
Prostatic Hyperplasia: AUA Guideline Vol. 200, 1-8, September 2018

10. Zou Z, Xu A, Zheng S, Chen B, Xu Y, $\mathrm{Li} \mathrm{H}$, Duan C,Zheng J,Chen J, Li C,Wang Y, Gao Y,Liang C,Liu C. Dual-centre randomized-controlled trial comparing transurethral endoscopic enucleation of the prostate using diode laser vs. bipolar plasmakinetic for the treatment of LUTS secondary of benign prostate obstruction: 1-year follow up results World Journal of Urology February 2018 https://doi.org/10.1007/s00345-0182229-3

11. Wu G, Hong Z, Li C, Bian C,Huang S, $\mathrm{Wu}$ D. A comparative study of diode laser and plasmakinetic in transurethral enucleation of the prostate for treating large volume benign prostatic hyperplasia: a randomized clinical trial with 12-month follow-up 14 January 2016, Springer-Verlag London 2016 Lasers Med Sci. https://doi.org/ 10. 1007/s10103-016-1883-1

12. El-Tabey M, Abo-Taleb A, Abdelal A, Khalil M. Outcome of Transurethral Plasmakinetic Vaporization for Benign Prostatic Hyperplasia 2015 Int Braz J Urol Vol. 41 (2): 239-244, March April, 2015 doi: 10.1590/S16775538.IBJU.2015.02.08

13. Abou-Taleb A, El-Shaer W, Saber W, Gharib T, Elshaer A. Bipolar Plasmakinetic Enucleo-Resection of the Prostate; Our experience with 245 patients for 3 years of follow up. 2017 Journal of Endourology DOI: 10.1089/end.2016.0746

14. Mithani M, El Khalid S, Khan S, Sharif I, Awan A, Mithani S, Majeed I. Outcome of $980 \mathrm{~nm}$ diode laser vaporization for benign prostatic hyperplasia: A prospective study Investig Clin Urol 2018;59:392-398. https://doi.org/10.4111/icu.2018.59.6.39 2 
Hassan S. Shaker, et al.,

دراسة مقارنة بين نتائج و مضاعفات تبخير البروستاتا بجهاز البلازما مقابل تبخير البروستاتا بجهاز

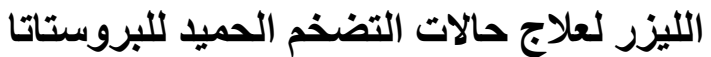

حسن سيد شاكر، هشام الثواف، محمد أبو النجا، محمد أحمد عبد الحميا

قسم جر احة المساللك البولية، كلية الطب، جامعة عين شمس

الخلفية: يعتبر تضخم البروستاتا الحميد أحد أكثر الأسباب شيوعًا لأعراض المسالك البولية السفلى ، والانسداد

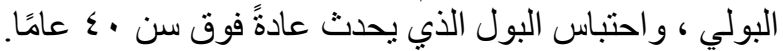

الهدف من الدراسة: مقارنة فعالية ومضاعفات تبخير البروستاتابالبلازما ثنائية القطب مقابل تبخير البروستاتا بالليزر

على مدى 1 أشهر من فنرة المتابعة المقارنة اللاحقة للعمليات الجر احية.

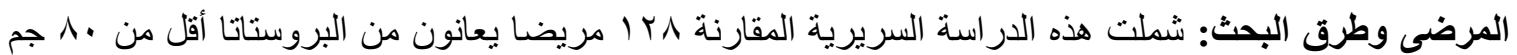

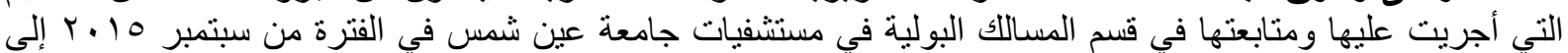

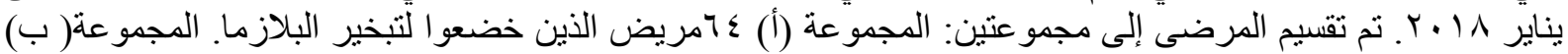

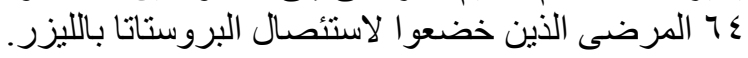

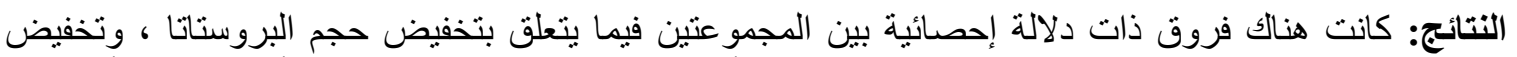

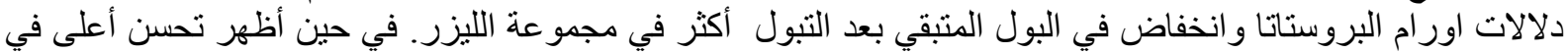

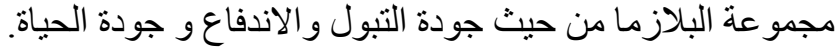

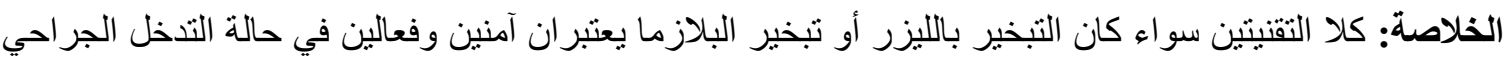

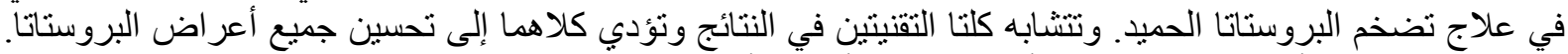

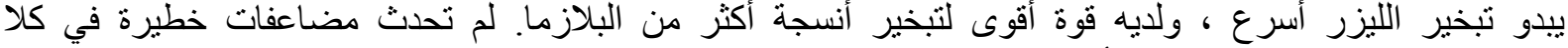

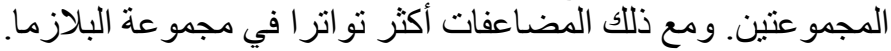

